\title{
Hypertext Markup Language
}

National Cancer Institute

\section{Source}

National Cancer Institute. Hypertext Markup Language. NCI Thesaurus. Code C142380.

A standard markup language used to display content on a web page, as specified by the World Wide Web Consortium (W3C). 